\title{
Within-lake variability of subfossil chironomid assemblage in a large, deep subtropical lake (Lugu lake, Southwest China)
}

\author{
Enlou ZHANG,${ }^{1 *}$ Yanmin CAO, ${ }^{1,2}$ Peter LANGDON,${ }^{3}$ Qian WANG,${ }^{1}$ Ji SHEN,${ }^{1}$ Xiangdong YANG ${ }^{1}$ \\ ${ }^{1}$ State Key Laboratory of Lake Science and Environment, Nanjing Institute of Geography and Limnology, Chinese Academy of \\ Sciences, Nanjing 210008, China; ${ }^{2}$ Graduate School of the Chinese Academy of Sciences, Beijing 100049 , China; ${ }^{3}$ School of \\ Geography, University of Southampton, SO17 1BJ Southampton, England, UK. \\ *Corresponding author: elzhang@niglas.ac.cn
}

\begin{abstract}
The present study analysed the distribution of subfossil chironomid larval head caspules in a suite of surface sediment samples from a large deep subtropical lake, i.e. Lugu lake, located in Southwest China. In order to identify the relationships between environmental variables and the chironomid assemblages ordination methods were used. A total of 41 chironomid taxa were found across the 46 samples, 21 of which had a minimum abundance $>1 \%$ and were present in more than one site. The samples were dominated by 12 taxa, which together accounted for 97\% of the fauna. Redundancy analysis (RDA) revealed that the predominant drivers of chironomid distribution within Lugu lake were bottom water temperature, water depth, loss-on-ignition (LOI) and water total phosphorus (TP) concentration. Abrupt changes in chironomid assemblages occurred at $10 \mathrm{~m}$ of water depth, which is closely related to the macrophyte distribution and the position of the thermocline. The chironomid assemblages became uniform below a water depth of ca. $15 \mathrm{~m}$, and the anthropogenic impact on the chironomid fauna was then limited to the edge of Lugu lake. The depth-related faunal shifts primarily reflect the dominant controls of temperature and macrophyte distribution on the chironomids in Lugu lake. This is the first within-lake subfossil chironomid study from this region and the understanding of key environmental influences on contemporary faunas within the lake will aid interpretations of palaeolimnological datasets to reconstruct past trends and magnitude of environmental change over a range of timescales.
\end{abstract}

Key words: subfossil chironomid, Lugu lake, within-lake variability, numerical analyses, environmental variables.

Received: March 2012. Accepted: July 2012.

\section{INTRODUCTION}

Chironomid larvae frequently are the most abundant insects in freshwater ecosystems (Cranston, 1995). Subfossil chironomids are widely employed for palaeoenvironmental studies due to their sensitivity to environmental changes and the good preservation of head capsules in lake sediments (Walker, 2001). Over recent decades, subfossil chironomids from lake sediments have been used to reconstruct quantitatively past environmental changes including July air temperature (Brooks, 2006; Walker and Cwynar, 2006), salinity (Eggermont et al., 2006; Heinrichs and Walker, 2006; Zhang et al., 2007) and nutrients (Brodersen and Quinlan, 2006; Langdon et al., 2006; Zhang et al., 2006). Given that most palaeolimnological studies using the subfossil chironomids are based on one core from one lake, and that transfer functions are developed from a single surface-sediment sample taken from the centre of each lake comprising the training set, understanding the patterns related to the within-lake distribution of fossil remains may improve the quality of the environmental reconstruction (Frey, 1988; Heiri et al., 2003; Eggermont et al., 2007; Kurek and Cwynar, 2009; Holmes et al., 2009). Previous studies on the within-lake distribution of chironomid assemblages (Heiri, 2004; Kurek and Cwynar, 2009; Holmes et al., 2009; Engels and Cwynar, 2011; Luoto, 2012) suggest that lake depth is an important variable influencing the chironomid distribution because numerous factors - such as water temperature, substrate, food availability, hypolimnetic oxygen, wind-induced currents, and distribution of aquatic macrophytes - vary with water depth. The influence of lake depth on palaeotemperature reconstruction has also been examined (Heiri et al., 2003; Holmes et al., 2009; Kurek and Cwynar, 2009). Most of these studies found that the sampling locations within the lake did affect, to some extent, the chironomid assemblages and associated inferred temperatures, although the extent to which chironomid remains are moved offshore in different studies are not consistent regardless of the depth of the studied lakes. Hence, it would appear that the influence of the lake's morphometry is still not completely resolved (Eggermont et al., 2007). Furthermore, most of the studies on within-lake variations of chironomid assemblages have been undertaken in shallow northern temperate lakes. Although there is great potential for reconstructing past environmental change using sub- 
fossil chironomids in different regions of China (Zhang et al., 2006, 2007, 2010), with much now known about chironomid distribution within lakes in SW China on the Yunnan plateau (Zhang et al., 2011), little is known about the within-lake distribution of chironomid assemblages in deep stratified lakes from this region.

Lugu lake is an alpine graben lake in Northwest Yunnan province and its hydrology is mainly influenced by the relative strength of the Indian monsoon. It is an ideal site for palaeolimnological study due to stable and continuous sedimentation rates, no industrial pollution and low population density within the catchment. In recent years, however, Lugu lake has been subject to increased tourism and agricultural improvements due to mechanisation which may have altered sedimentation patterns. The Lugu lake area has recently been desiginated as a nature reserve (Wu et al., 2008). In this study, the subfossil chironomid assemblages from surface sediment samples taken from a number of sites along the water depth gradient are analysed. The aims of this study are: i) to identify the variability of chironomid assemblages related to water depth within the dimictic lake; ii) to understand the key environmental influences - besides depth - on contemporary faunas within the lake, which will aid the interpretation of palaeolimnological data sets to reconstruct past trends and observe the magnitude of environmental change over a range of timescales.

\section{METHODS}

\section{Study sites and sampling}

Lugu lake $\left(27^{\circ} 41^{\prime}-27^{\circ} 45^{\prime} \mathrm{N}, 100^{\circ} 45^{\prime}-100^{\circ} 50^{\prime} \mathrm{E}, 2690\right.$ $\mathrm{m}$ asl) is located in Ninglang county, Yunnan province, on the southeast margin of the Tibetan plateau (Fig. 1), and is currently a clear and oligotrophic lake with a secchi depth of $11 \mathrm{~m}$ and total phosphorus (TP) concentration of 18.5 $\mu \mathrm{g} \cdot \mathrm{L}^{-1}$ in the openwater area. It is a semi-closed deep graben lake and has a maximum depth of $93.5 \mathrm{~m}$ and a mean depth of $40.3 \mathrm{~m}$, with a total surface water area of $48.45 \mathrm{~km}^{2}$ and drainage area of $171.4 \mathrm{~km}^{2}$ (Wang and Dou, 1998). The hydrology of Lugu lake is dominated by the southwest Indian monsoon, and the climate in this region is temperate with distinct dry and wet seasons. Approximately $80-90 \%$ precipitation happens between May and October. The mean annual air temperature is around $12.8^{\circ} \mathrm{C}$ and annual precipitation is around $1000 \mathrm{~mm}$. The lake is mainly charged by karst groundwater and precipitation. It is located in the catchment of the Yalong river, a tributary of the Yangtze river. The most common rock types in the catchment are limestone, mudstone and sandstone. The soil types mainly include Alfisols, Oxisols, Entisols and Mollisols (Wang and Dou, 1998). The lake's submerged macrophytes are dominated by Ottelia acuminata, Potamogeton pectinatus and Potamogeton tepperi, which are distributed on the edge of the lake in water depth $<11 \mathrm{~m}$ (Wang and Dou, 1998). Terrestrial catchment vegetation is mainly the conifers Pinus yunnanensis var. faranch and Pinus tabuliformis.

Surface-sediment samples $(0-1 \mathrm{~cm})$ were collected with a Kajak gravity corer from 46 sites along the depth gradient of the lake in August 2010 (Fig. 1). Meanwhile, the distribution of macrophytes was surveyed. Water samples were also collected at each site. Water depth, Secchi depth, water temperature, dissolved oxygen (DO), $\mathrm{pH}$ and conductivity were measured in the field using an YSI 650 multi-parameter display system (model 650 MDS; YSI

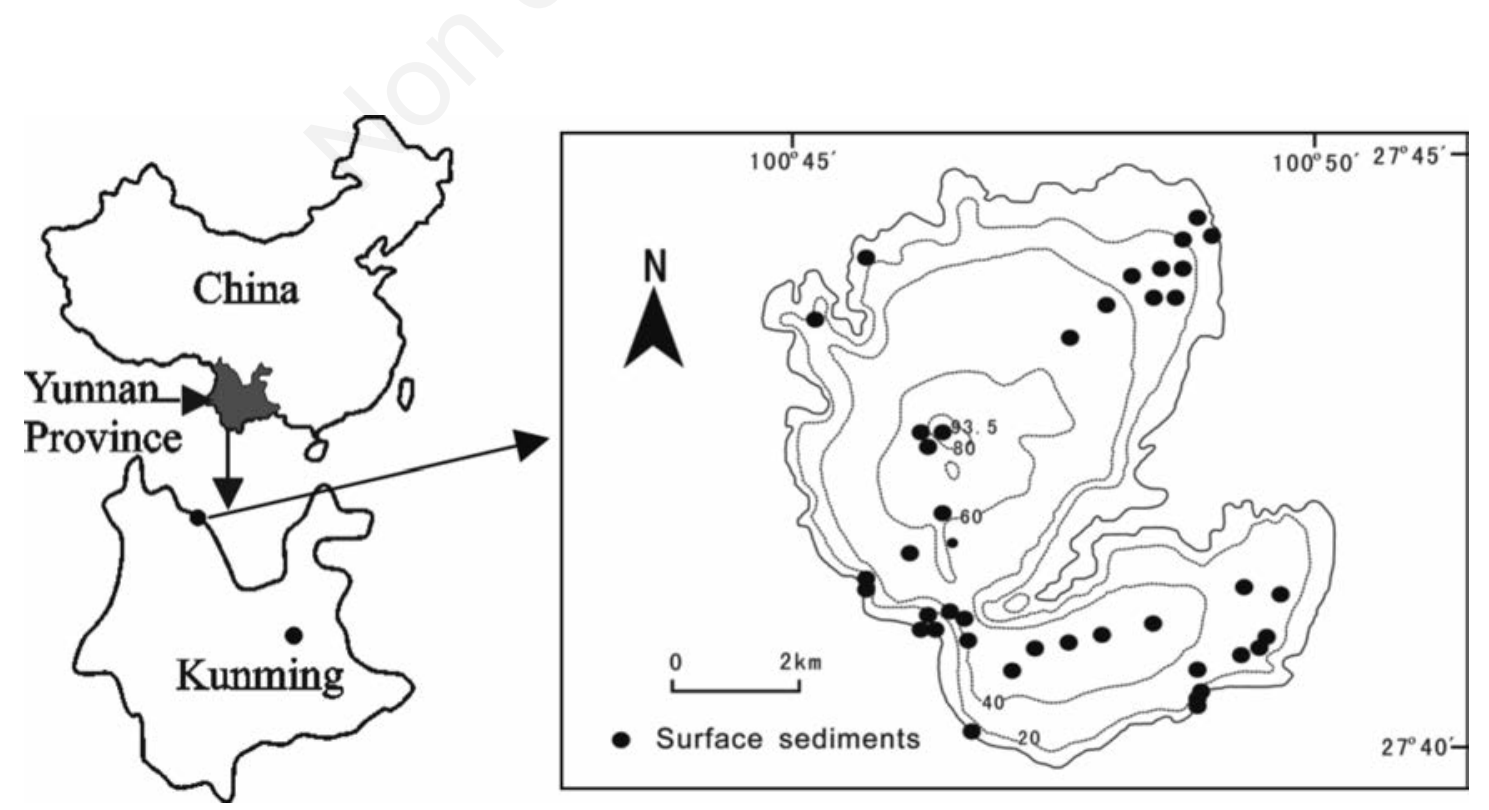

Fig. 1. Location and sampling sites of Lugu lake. 
Inc., Yellow Springs, OH, USA) with a $600 \mathrm{XL}$ probe. Additional chemical variables were measured in the laboratory. Total nitrogen (TN), total phosphorus (TP) and concentration of $\mathrm{HCO}_{3}^{-}$and $\mathrm{CO}_{3}{ }^{2-}$, and Chlorophyll-a (Chl-a) were analysed using Water and Waste water Monitoring Methods (EPA, 2002). Loss-on-ignition (LOI) and grain size of the surface sediment were also calculated.

\section{Chironomid analysis}

Surface sediment samples were analysed for chironomids by following standard methods (Brooks et al., 2007). The sediment was deflocculated in $10 \%$ caustic potash $(\mathrm{KOH})$ in a water bath at $75^{\circ} \mathrm{C}$ for $15 \mathrm{~min}$. The samples were then sieved at 212 and $90 \mu \mathrm{m}$ and the residue was examined under a stereo-zoom microscope at $\times 25$. All the head capsules found were mounted on microscope slides in a solution of Hydromatrix ${ }^{\circledR}$. The chironomid head capsules were identified mainly following Wiederholm (1983), Oliver and Roussel (1983), Rieradevall and Brooks (2001), and Brooks et al. (2007).

\section{Numerical and statistical analyses}

All taxa recovered from the 46 samples were categorised into three units. A taxon would be defined as rare if it failed to exceed 3 occurrences. In fact, if it exceeded 3 occurrences, the taxon would be identified as either common or uncommon when its mean frequency exceeded or remained below one specimen per sample, respectively (Eggermont et al., 2007). The chironomid diversity was assessed using species richness (calculated as the total number of species), Shannon-Wiener index (Shannon and Weaver, 1963) and Hill's N2 (Hill, 1973).

A range of numerical methods were used to determine the influence of the environmental variables on the chironomids distributions within the lake. Environmental variables - except $\mathrm{pH}$ - were $\log _{10}(\mathrm{x}+1)$ transformed prior to ordi- nation analysis. Species with a maximum abundance $<1 \%$ or an occurrence in only one sample were removed prior to numerical analyses. A detrended correspondence analysis (DCA) (Hill and Gauch, 1980) with detrending by segments and non-linear rescaling was used to identify the gradient length within the chironomid data in order to check whether unimodal analysis was appropriate (ter Braak, 1987). Detrended correspondence analysis results showed that the axis 1 gradient length was 1.815 standard deviations, indicating that linear analysis was suitable. Direct gradient ordination by redundancy analysis (RDA) with automatic selection was used to identify significant $(\mathrm{P} \leq 0.05)$ explanatory variables that explained the chironomid distribution (ter Braak and Šmilauer, 2002). Monte Carlo permutation tests (499 permutations) were employed to test the significance of each variable. Variance inflation factors (VIFs) were examined via a series of RDAs on all the significant variables, and variables with high VIFs $(>20)$ were excluded from further analysis (Hall et al., 1999). Then, partial RDAs were performed to calculate the explained variance in the chironomid data by the unique effects of the individual variables selected in the forward-selection. All analyses were based on square root transformed percentage data with downweighting of rare taxa, and the program CANOCO version 4.5 was used for ordination analysis (ter Braak and Šmilauer, 2002). Chironomid percentage diagrams were produced with software TILIA and TGView 2.02 (Grimm, 1990, 2004). Midge zones in surface sediments were identified using the constrained incremental sum of squares (CONISS) based on square-root transformation of species data.

\section{RESULTS}

\section{Physical and chemical variables in Lugu lake}

Bottom water temperature ( $\mathrm{T}$ ) ranged from 7.2 to $22.9^{\circ} \mathrm{C}$ with a mean and median value of 13.5 and $11.0^{\circ} \mathrm{C}$,
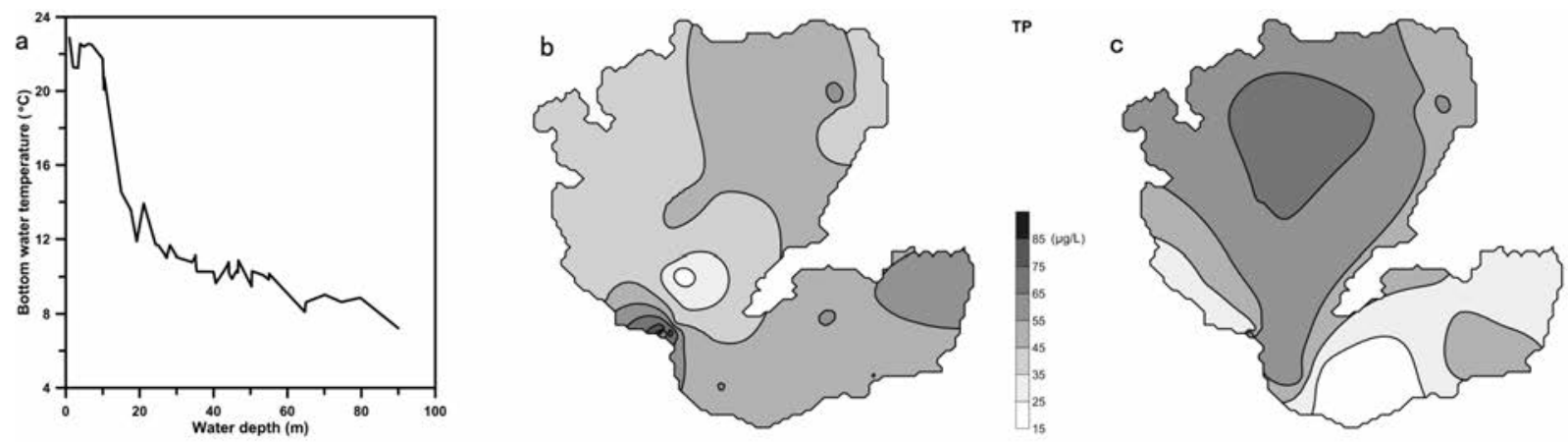

Fig. 2. Selected environmental parameters gradient in Lugu lake: a) bottom temperature $v s$ water depth; b) TP (total phosphorus) concentration; c) LOI (loss-on-ignition) of surface sediment. 
respectively. The lake is alkaline, with $\mathrm{pH}$ values changing in the spectrum from 8.5 to 9.3. A large conductivity gradient was measured and varied from 109 to $210 \mu \mathrm{S} \mathrm{cm}^{-1}$, with an average value of $206 \mu \mathrm{S} \mathrm{cm}^{-1}$ [there was an abnormally low value $\left(2 \mu \mathrm{S} \mathrm{cm}^{-1}\right)$ in site 41$]$. The lake is oligotrophic, with relatively low nutrient concentrations; TP ranged between 18.5 and $87.4 \mu \mathrm{g} \mathrm{L}^{-1}$, with a mean value of $50.8 \mu \mathrm{g}$ $\mathrm{L}^{-1}$. The distribution of the water TP concentration within the lake shows that high TP values is only limited to the lake edge (Fig. 2b). Total nitrogen ranged from 80.4 to 318 $\mu \mathrm{g} \mathrm{L} \mathrm{L}^{-1}$ (with average of $164.8 \mu \mathrm{g} \mathrm{L}^{-1}$ ), and Chl-a from 0 to $707.3 \mu \mathrm{g} \mathrm{L}^{-1}$ (with average of $20.6 \mu \mathrm{g} \mathrm{L}^{-1}$ ). The macrophytes were distributed on the edge of the lake in water depth $<11 \mathrm{~m}$, which is similar to a previous study (Wang and Dou, 1998).

\section{Chironomid assemblages and species diversity}

Forty-one chironomid taxa were identified from the samples. Among them, 21 chironomid taxa had a maximum relative abundance $>1 \%$ and occurred in more than two samples from 46 sites. The relative abundance and concentration of 21 principle chironomid taxa are presented along the depth gradient in Figs. 3a and b. According to the criteria for judging chironomid appearance frequency (Eggermont et al., 2007), of the total taxa, 12 common types together accounted for $97 \%$ of the total number of chironomid head capsules extracted from all sampes and the average abundances across the whole lake ranged from 1.0 to $29.6 \%$. The abundance of Tanytarsus mendax-type (29.6\%), Procladius (19.5\%), Polypedilum nubeculosum-type (13.3\%), and Paratanytarsus penicillatus-type (10.8\%) exceeded $10 \%$ of the total chironomid head capsules, respectively. Only 6 taxa were classified as uncommon, which together made up 2\% of the total number of chironomid head capsules. The remaining 22 taxa were rare and only occupied less than $1 \%$ of the total head capsules in all.

Chironomid assemblages showed an obvious change from the near-shore to offshore. P. penicillatus-type, Chironomus anthracinus-type and Paramerina were the dominant taxa in samples in the near-shore area with water depth $<10 \mathrm{~m}$ (Zone 2). These littoral sediments also contained relatively high chironomids head capsules (11-33 head capsules per gram of wet sediments) (Fig. 4) and high richness of species (12-20 taxa) (Fig. 5). Species' evenness (Hill's N2) was the highest (5.4-9.1) and had a similar pattern to species diversity.

An obvious assemblage change was apparent at the boundary depth of $10 \mathrm{~m}$. Zone $1 \mathrm{~d}$ (from 10 to $17 \mathrm{~m}$ ) comprised a few samples with a high relative abundance of Microchironomus, differing from other chironomid communities. T. mendax-type and Procladius taxa replaced the dominance of $P$. penicillatus-type and $C$. anthracinustype in zone 1c (from 17 to $33 \mathrm{~m}$ ), and their abundances rose with increases in water depth. The percentage of $P$. nubeculosum-type maintained a steady amount in this mid-depth area. Particularly, the development of Monodiamesa was limited to this depth spectrum. As the water depth increased, the abundance of chironomids, species diversity and evenness all declined.

The chironomid composition in zone $1 \mathrm{~b}$ (from 33 to $73 \mathrm{~m}$ ) appeared to be similar to zone 1c. T. mendax-type showed a slight decline after its peak around $45-50 \mathrm{~m}$, while Procladius displayed a converse trend. There was no obvious change between these two mid-depth areas in chironomid concentration and species richness.

Three samples from deepest water $(>70 \mathrm{~m})$ comprised zone 1a, which possessed relatively low species diversity (4-7) and evenness (2.2-2.5). Several chironomid species were absent in this zone, such as Ablabesmyia and C. anthracinus-type.

Additionally, as mentioned above, the concentration of head capsule and species diversity combined with Hill's $\mathrm{N} 2$ were negatively correlated with water depth, with the correlation coefficients $-0.62,-0.74$ and $-0.72(\mathrm{P}<0.001)$, respectively. The chironomid diversity (Shannon-Wiener index) was low, with an average diversity of 1.51 in the sites, and none of the sites exceeded 2.4 (Fig 4). A similar pattern is observed between diversity (Shannon-Wiener index) (Fig. 4) and species richness (Fig. 5), with higher values in the littoral area and lower values in the deep area.

\section{Ordinations}

The final calibration data set consisted of 13 measured environmental variables and 21 chironomid taxa with a maximum abundance $>1 \%$ and occurred in more than two samples from 46 sites. An initial RDA with all 13 environment variables explained $56.3 \%$ of total variance in the chironomid data. Of the variations in the chironomid assemblages, $45.4 \%$ were explained by the first two RDA axes (Fig. 6). Bottom temperature (10.8\% of the explained variance), water depth (3.3\% of the explained variance), LOI (3.0\% of the explained variance) and water TP $(2.6 \%$ of the explained variance) comprised the minimum subset of significant environmental factors $(\mathrm{P}<0.05)$ explaining $47.7 \%$ of the cumulative chironomid variances (Tab. 1). Bottom temperature was negatively correlated with water depth, ( $\mathrm{r}=-0.86, \mathrm{P}<0.001)$ (Figs. 2a and 6) after removal from the RDA analyses, then the water depth was more significant with both improved $P$ values and the unique explained variance percentage (Tab. 1).

\section{DISCUSSION}

Chironomid larval head capsule concentrations were higher in samples from near-shore shallow sites. This phenomenon was also found in other studies, and the reasons are usually attributed to sediment winnowing and focusing, as well as physiological gradients related to water 

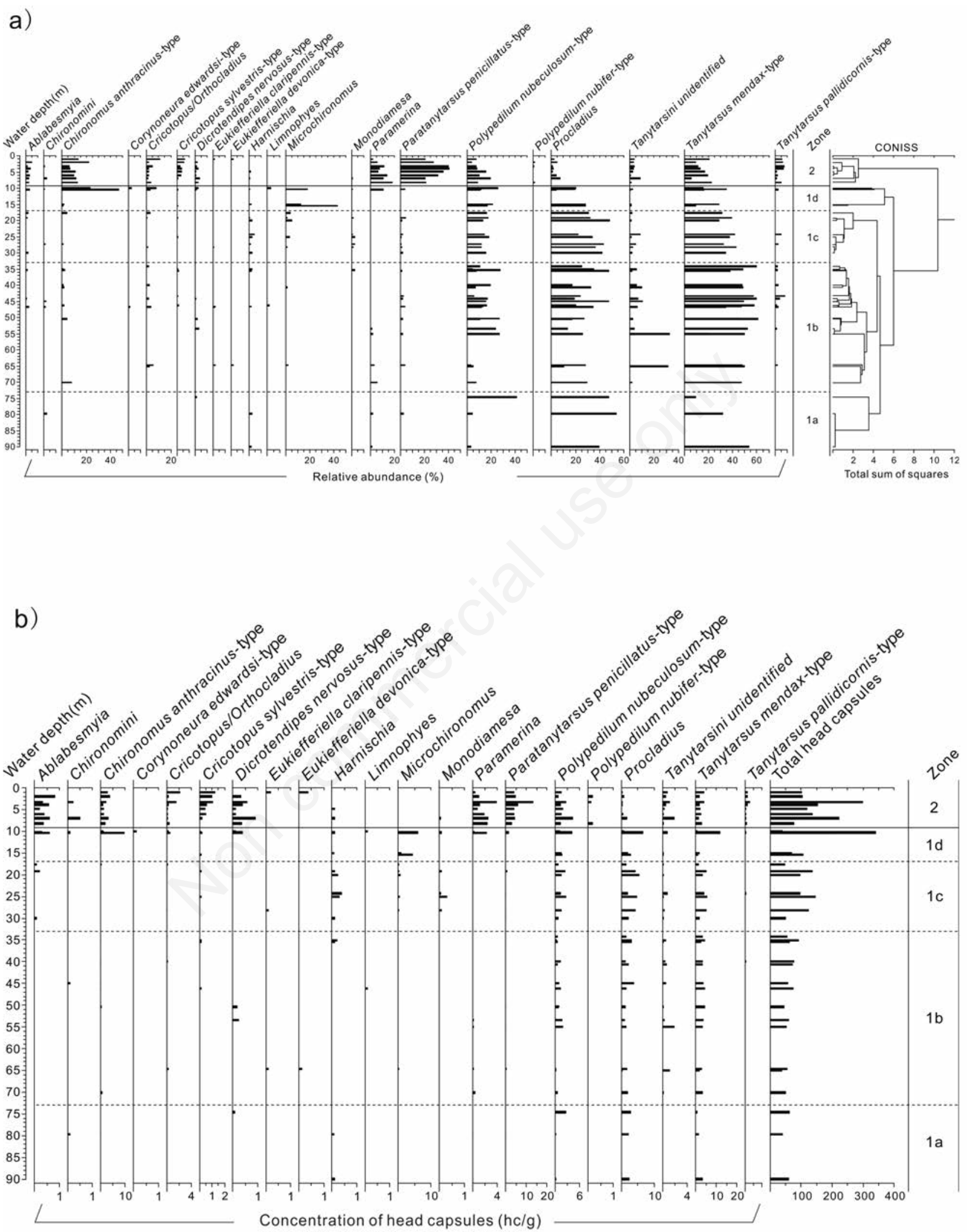

Fig. 3. Distribution of main chironomid taxa in surface-sediment assemblages from Lugu lake. Zones were indentified by CONISS analysis along the water depth of sampling sites. a) relative abundance; b) concentration of head capsules. 


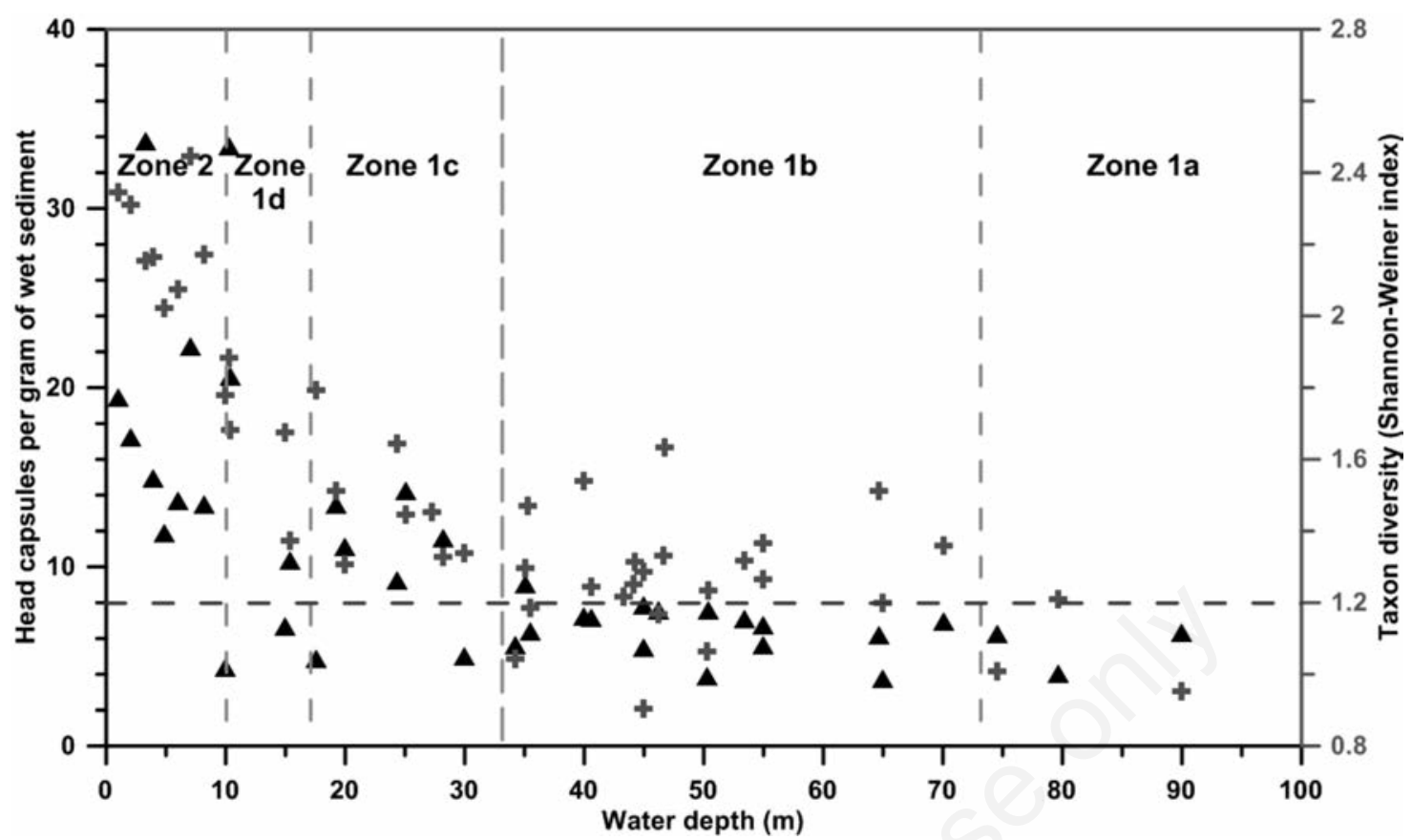

Fig. 4. Scatter plots of concentrations of chironomid presented by head capsules per gram of wet sediment (triangles) and ShannonWiener index (crosses) along with water depth. The vertical bars on the graphs are based on a depth-constrained cluster analysis. Zones are classified according to different water depths as follows: zone 2 is $<10 \mathrm{~m}$; zone $1 \mathrm{~d}$ ranges from 10 to $17 \mathrm{~m}$; zone $1 \mathrm{c}$ from 17 to 33 $\mathrm{m}$; zone $1 \mathrm{~b}$ from 33 to $73 \mathrm{~m}$; and zone $1 \mathrm{a}$ is $>73 \mathrm{~m}$.

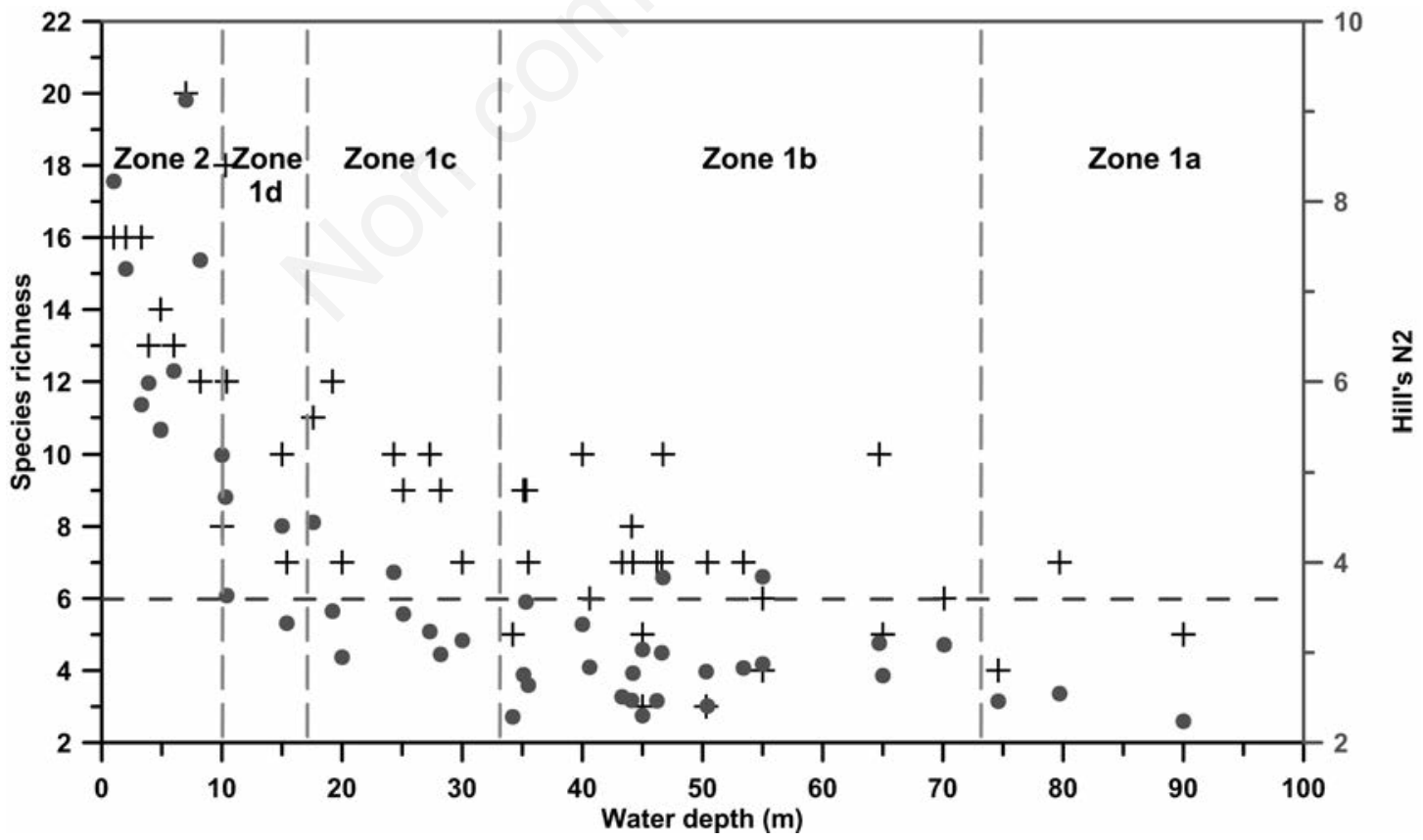

Fig. 5. Scatter plot showing species richness (crosses) and Hill's N2 (grey circles) in different zones along with water depth. The vertical bars on the graphs are based on a depth-constrainews: zone 2 is <10 m; zone $1 \mathrm{~d}$ ranges from 10 to $17 \mathrm{~m}$; zone $1 \mathrm{c}$ from 17 to $33 \mathrm{~m}$; zone $1 \mathrm{~b}$ from 33 to $73 \mathrm{~m}$; and zone $1 \mathrm{a}$ is $>73 \mathrm{~m}$. 
depth (cf. Eggermont et al., 2007; Holmes et al., 2009; Schmäh, 1993). In Lugu lake, higher concentration nearshore may be also primarily due to the fact that large amounts of submerged macrophytes were distributed within the shallow parts of the lake at less than $11 \mathrm{~m}$ of depth (Wang and Dou, 1998), which in turn support large invertebrate communities. The taxa associated with macrophytes, such as $P$. penicillatus-type, Ablabesmyia, Cricotopus sylvestris-type, Paramerina, Dicrotendipes nervosus-type (Brodersen et al., 2001; Langdon et al., 2010; Gathorne-Hardy et al., 2007), were restricted to the near-shore locations at a depth less than $11 \mathrm{~m}$. This also confirms the relationship between macrophytes and the chironomid fauna in Lugu lake. Furthermore, Fig. 6 indicates that the samples at the edge of the lake had coarser sediment grain size and higher TP concentration in water column. The high nutrient loading from human activities, including tourism and agriculture in the catchment, mainly influences the shallow offshore area, favouring the development of plankton, and thus supports the high concentration of chironomid fauna. Lower chironomid concentration in deeper locations may be due to the fact that Lugu lake is a deep seasonally stratified lake, and lower temperature and seasonally anoxic hypolimnion lead to low chironomid production (Schmäh, 1993). Monitoring during 2010 shows that Lugu lake behaves as a typical warm monomictic lake. In summer and autumn the lake water is stratified, while during early spring and winter the lake is unstratified (Wang et al., unpublished data). Various studies show that the extent to which chironomid remains are moved offshore is not consistent, regardless of depth and morphometry (Schmäh, 1993; Heiri, 2004; Eggermont et al., 2007). In Lugu lake, several chironomid taxa, such as $P$. penicillatus-type, C. anthracinus-type, Ablabesmyia, C. sylvestris-type, Paramerina, Cricotopus/Orthocladius, D. nervosus-type, Tanytarsus pallidicornis-type, were restricted to shallow sites, indicating that the transportation of littoral head capsules into the

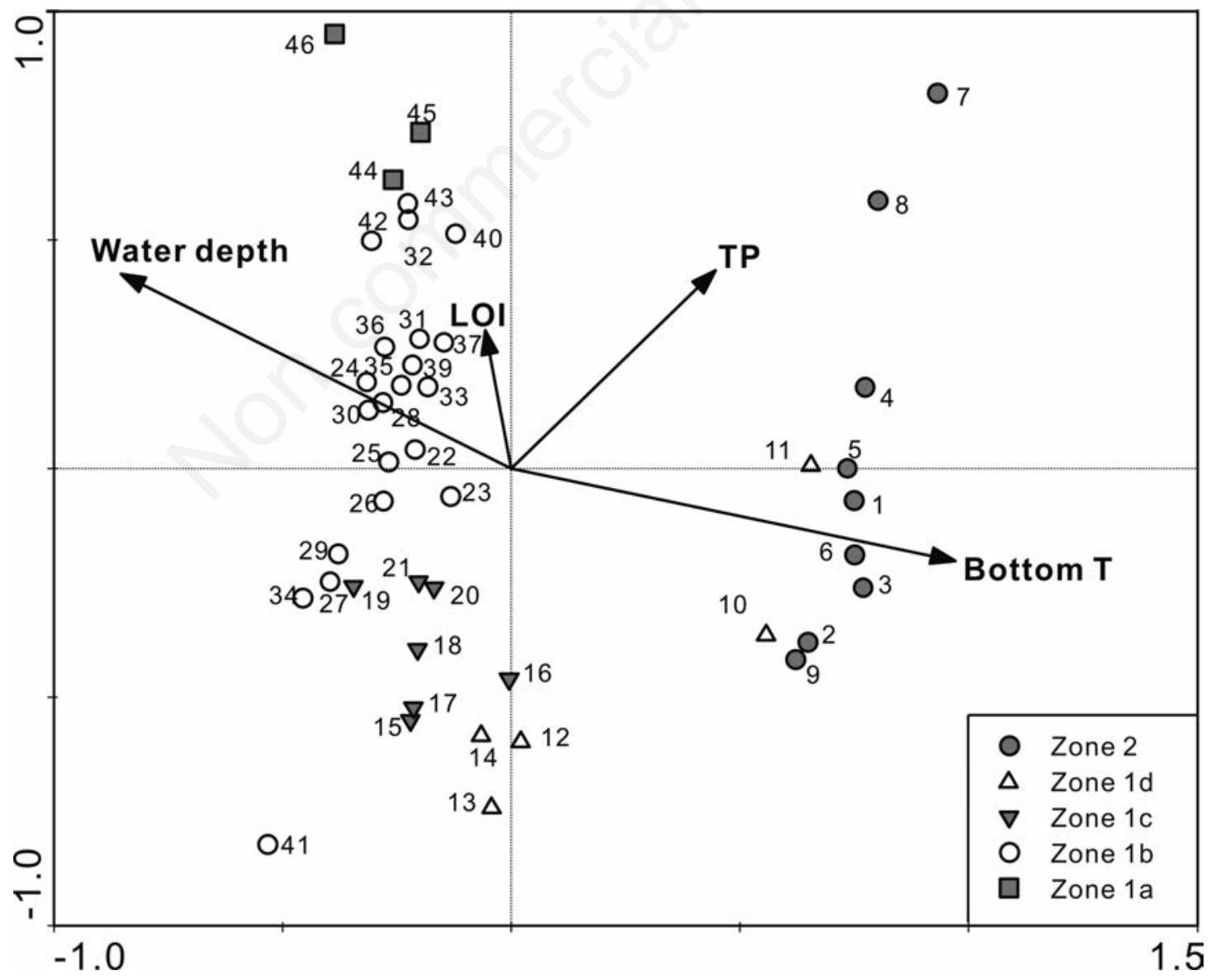

Fig. 6. Scatter biplot of the chironomid assemblage and the environmental variables [bottom water temperature (Bottom T), water depth, loss-on-ignition (LOI), and water total phosphorus (TP)] for the samples from Lugu lake. 
deeper parts of the lake is minimal. This may be due to the fact that the wind-driven current can only influence the near-shore locations of such a large lake with a depth $<30 \mathrm{~m}$ (Wang and Dou, 1998).

Redundancy analyses revealed that the predominant drivers of chironomid distribution within the Lugu lake were the influence of bottom water temperature, water depth, LOI and water TP (Fig. 6). As a large deep stratified dimictic lake, the thermocline of Lugu lake extends between 10 and $17.5 \mathrm{~m}$ in July and the temperature of the epilimnion is about $10^{\circ} \mathrm{C}$ higher than that of the hypolimnion. The position of the thermocline of Lugu lake has a significant influence on the distribution of macrophytes and the substrate, thus influencing the composition of the chironomid communities. Water depth negatively correlates with water temperature (Figs. 2a and 6) and has a strong influence on the distribution of chironomid larvae with many taxa showing depth preferences. Similar patterns are also reported in other studies (Brundin, 1949; Schmäh, 1993; Heiri, 2004). Water depth is commonly significant in driving the distribution and abundance of chironomids (Larocque et al., 2001; Barley et al., 2006) and models have been developed to reconstruct lake water depth using chironomids (Korhola et al., 2000; Luoto, 2009). Water depth is closely related to temperature, food availability and oxygen conditions, which in turn determine the composition of chironomid communities in the profundal zone of regularly stratified lakes (Lindegaard, 1995). Typically the chironomid assemblages become uniform below ca. $15 \mathrm{~m}$ (Kurek and Cwynar, 2009). Loss-onignition is another important environmental driver of the chironomid distribution and abundance within Lugu lake. Loss-on-ignition has also been found to be important in other chironomid training sets (Nyman et al., 2005; Langdon et al., 2008). Loss-on-ignition can influence the composition of chironomid communities through a range of mechanisms, including relationships with substrate, lake productivity and larval feeding strategies. Fig. $2 \mathrm{c}$ shows that the sites with higher LOI were mainly distributed in deep central areas with fine grain sizes.

Lakes on the Yunnan plateau have changed considerably in recent decades as a consequence of a rapid eco- nomic development. In addition, the chironomid data set from lakes in this region indicates that depth and DO are key environmental factors influencing contemporary faunas (Zhang et al., 2011). Lugu lake is located in a rural alpine area, and is still oligotrophic. Bottom DO is higher than in other deep eutrophic lakes on the Yunnan plateau (Zhang et al., 2011). In recent years, however, Lugu lake has become a nature reserve, thus it has been facing pressure from the huge number of visitors, but also from improved agricultural techniques (Wu et al., 2008). Pollution caused by human activities is currently limited to the lake edge, as indicated by the distribution of the water TP concentration within the lake (Fig. 2b) and its effect on the chironomid assemblage in these sites.

Obvious changes in the chironomid assemblages were apparent at $10 \mathrm{~m}$ of water depth. The concentration of head capsules, evenness and richness of species were higher in samples located at $<10 \mathrm{~m}$. The upper boundary of the thermocline is at about $11 \mathrm{~m}$ in July, which approximates to a major change in the chironomid assemblage at this depth. The position of the thermocline is recognised as an important boundary with respect to many lake processes (Wetzel, 2001), and may also structure withinlake chironomid distribution patterns. Furthermore, the thermocline also occurs at a depth where macrophytes can survive in Lugu lake, and the presence of macrophyte communities provides more microhabitats. This results in higher species richness and concentration of chironomids. In Lugu lake depth-related faunal shifts primarily reflect the dominant controls of temperature and macrophyte distribution on the chironomids.

There are clear relationships between diversity (species richness and Shannon-Wiener index) and environmental factors. The chironomid diversity decreases along the depth and bottom water temperature gradients. However, the chironomid diversity (Shannon-Wiener index) is relatively low, with an average diversity of 1.51 , and none of the sites sampled exceeded 2.4. The anomalously low chironomid diversity is similar to that of the lakes on Yunnan plateau (Zhang et al., 2011). Human impact, such as enhanced soil erosion of the catchment and increased nutrient level of the

Tab. 1. Results of partial redundancy analyses for the significant variables including/excluding the bottom water temperature.

\begin{tabular}{ccccc}
\hline & Variable & Significance (P value) & $\lambda 1 / \lambda 2$ & Explained percent of total variance (\%) \\
\hline Run 1 & Bottom water temperature & 0.002 & 0.77 & 10.8 \\
& Water depth & 0.014 & 0.24 & 3.3 \\
& LOI & 0.02 & 0.21 & 3.0 \\
& TP & 0.044 & 0.19 & 2.6 \\
\hline Run 2 & Water depth & 0.002 & 1.23 & 24.8 \\
& LOI & 0.028 & 0.17 & 3.5 \\
& TP & 0.036 & 0.17 & 3.4 \\
\hline
\end{tabular}

LOI, loss-on-ignition; TP, total phosphorus. 
lake in recent years, may be a possible reason for this phenomenon. The chironomid fauna of the samples from the deep area of Lugu lake is similar to that of the deep lakes in Yunnan, which usually have low species richness and are dominated by taxa such as Procladius and Tantarsus genus (Zhang et al., 2011).

Taken together, water depth - which interacts with bottom temperature - is the most significant environmental variable forcing chironomid composition and distribution in a deep, plateau lake. Fossil chironomid gradient from near-shore to offshore can reflect the real living chironomid compositions near a specific habitat. In palaeolimnological studies, this means a deficient representativeness of single core for the whole lake basin. Substituting space for time, more attention should be paid to dominant factors potentially varying through time, either to avoid bias in palaeoenvironmental reconstructions or for modern lake management. For example, water depth is determined as the most important driver in faunal community, but nutrient loading resulting from anthropogenic interference might predominate if effective conservation protocols are not executed.

\section{CONCLUSIONS}

Ordination analyses reveal that the predominant drivers of chironomid distribution within the Lugu lake were the influence of bottom water temperature, water depth, LOI and water TP. The chironomid assemblage shows distinct depth-related faunal shifts, and an abrupt change in the chironomid distribution appears at $10 \mathrm{~m}$ of water depth. Several chironomid taxa were restricted to the shallow sites, which indicate that the transportation of littoral head capsules into deeper parts of the lake is minimal. The abrupt change in the chironomid assemblage is closely related to the macrophyte distribution and the position of the thermocline. There are only minor changes of chironomid assemblages below approximately $15 \mathrm{~m}$ of water depth. This may reflect the effects of temperature on the chironomid distribution, as the temperature falls rapidly between $0-15 \mathrm{~m}$, but less steeply in hypolimnion during summer. In Lugu lake depth-related chironomid faunal shifts primarily reflect the dominant controls of temperature and macrophyte distribution. Spatial heterogeneity in the chironomid structure demonstrates a high representativeness of fossil remains for pre-buried chironomid assemblages, but a defective substitution of a single core for the whole lake basin in palaeolimnology. Although anthropogenic impacts are still limited to the edge of Lugu lake, more attention need to be paid and farseeing strategies need to be developed to keep a sustainable development of the lake. Given the developing tourism and the scarcity of conservation protocols, this study gives some hints and warnings for initiatives of modern ecological management. The heterogeneity in chironomid commu- nities in such a stratified lake would also provide a reference case for sampling site selection in palaeolimnological studies. Additionally, the preference of specific species for water depth and their ecological limitations will aid the future interpretations of palaeolimnological data.

\section{ACKNOWLEDGMENTS}

This research was supported by the National Basic Research Program of China (2012CB956104 2010CB 950201) Nanjing Institute of Geography \& Limnology, CAS (NIGLAS2011KXJ002 2012135004), and National Natural Science Foundation of China (41272380 41072267).

The authors are also grateful to Dr. Min Yao for her help on fieldwork.

\section{REFERENCES}

Barley EM, Walker IR, Kurek J, Cwynar LC, Mathewes RW, Gajewski K, Finney BP, 2006. A northwest North American training set: distribution of freshwater midges in relation to air temperature and lake depth. J. Paleolimnol. 36:295-314.

Brodersen KP, Odgaard BV, Vestergaard O, Anderson NJ, 2001. Chironomid stratigraphy in the shallow and eutrophic Lake Søbygaard, Denmark: chironomid-macrophyte co-occurrence. Freshwater Biol. 46:253-267.

Brodersen KP, Quinlan R, 2006. Midges as palaeoindicators of lake productivity, eutrophication and hypolimnetic oxygen. Quaternary Sci. Rev. 25:1995-2012.

Brooks SJ, 2006. Fossil midges (Diptera: Chironomidae) as palaeoclimatic indicators for the Eurasian region. Quaternary Sci. Rev. 25:1894-1910.

Brooks SJ, Langdon PG, Heiri O, 2007. The identification and use of Palaearctic Chironomidae larvae in palaeoecology. QRA Technical Guide No. 10. Quaternary Research Association ed., London, UK: 276 pp.

Brundin L, 1949. [Chironomiden und andere Bodentiere der südschwedischen Urgebirgsseen. Ein Beitrag zur Kenntnis der bodenfaunistischen Charakterzüge schwedischer oligotropher Seen]. [in German]. Report from the Institute of Freshwater Research no. 30. Carl Blom Publ., Lund, Sweden: 914 pp.

Cranston PS, 1995. Introduction, p. 1-7. In P.D. Armitage, P.S. Cranston and L.C.V. Pinder (eds.) The Chironomidae: the biology and ecology of non-biting midges. Chapman and Hall, London, UK.

Eggermont H, De Deyne P, Verschuren D, 2007. Spatial variability of chironomid death assemblages in the surface sediments of a fluctuating tropical lake (Lake Naivasha, Kenya). J. Paleolimnol. 38:309-328.

Eggermont H, Heiri O, Verschuren D, 2006. Fossil Chironomidae (Insecta: Diptera) as quantitative indicators of past salinity in African lakes. Quaternary Sci. Rev. 25:1966-1994.

Engels S, Cwynar LC, 2011. Changes in fossil chironomid remains along a depth gradient: evidence for common faunal thresholds within lakes. Hydrobiologia 665:15-38.

EPA, 2002. Water and Waste water Monitoring Methods. $4^{\text {th }}$ ed. China Environmental Protection Administration. China Environmental Science Press, Beijing, China.

Frey DG, 1988. Littoral and offshore communities of diatoms, 
cladocerans, and dipterous larvae, and their interpretation in paleolimnology. J. Paleolimnol. 1:179-191.

Gathorne-Hardy FJ, Lawson IT, Church MJ, Brooks SJ, Buckland PC, Edwards KJ, 2007. The Chironomidae of Gróthúsvatn, Sandoy, Faroe Islands: climatic and lake-phosphorus reconstructions, and the impact of human settlement. Holocene 17:1259-1264.

Grimm EC, 1990. TILIA and TILIA GRAPH. PC spreadsheet and graphics software for pollen data. INQUA, Working Group on Data-Handling Methods. Newsletter 4:5-7.

Grimm EC, 2004. TGView. Illinois State Museum, Research Collection Center ed., Springfield, IL, USA.

Hall RI, Leavitt PR, Quinlan R, Dixit AS, Smol JP, 1999. Effects of agriculture, urbanization, and climate on water quality in the northern Great Plains. Limnol. Oceanogr. 44:739-756.

Heinrichs ML, Walker IR, 2006. Fossil midges and palaeosalinity: potential as indicators of hydrological balance and sealevel change. Quaternary Sci. Rev. 25:1948-1965.

Heiri O, 2004. Within-lake variability of subfossil chironomid assemblages in shallow Norwegian lakes. J. Paleolimnol. 32:67-84.

Heiri O, Birks HJB, Brooks SJ, Velle G, Willassen E, 2003. Effects of within-lake variability of fossil assemblages on quantitative chironomid-inferred temperature reconstructions. Palaeogeogr. Palaeocl. 199:95-106.

Hill MO, 1973. Diversity and evenness: a unifying notation and its consequences. Ecology 54:427-432.

Hill MO, Gauch HG, 1980. Detrended correspondence analysis: an improved ordination technique. Plant Ecol. 42:47-58.

Holmes N, Langdon PG, Caseldine CJ, 2009. Subfossil chironomid variability in surface samples from Icelandic lakes: implications for the production and use of training sets. J. Paleolimnol. 42:281-295.

Korhola A, Olander H, Blom T, 2000. Cladocera and chironomid assemblages as quantitative indicators of water depth in subarctic Fennoscandian lakes. J. Paleolimnol. 24:43-54.

Kurek J, Cwynar LC, 2009. Effects of within-lake gradients on the distribution of fossil chironomids from maar lakes in western Alaska: implications for environmental reconstructions. Hydrobiologia 623:37-52.

Langdon PG, Holmes N, Caseldine CJ, 2008. Environmental controls on modern chironomid faunas from NW Iceland and implications for reconstructing climate change. J. Paleolimnol. 40:273-293.

Langdon PG, Ruiz Z, Brodersen KP, Foster IDL, 2006. Assessing lake eutrophication using chironomids: understanding the nature of community response in different lake types. Freshwater Biol. 51:562-577.

Langdon PG, Ruiz Z, Wynne S, Sayer CD, Davidson TA, 2010. Ecological influences on larval chironomid communities in shallow lakes: implications for palaeolimnological interpretations. Freshwater Biol. 55:531-545.

Laroque I, Hall RI, Grahn E, 2001. Chironomids as indicators of climate change: a 100-lake training set from a subarctic region of northern Sweden (Lapland). J. Paleolimnol. 26:307-322.

Lindegaard C, 1995. Classification of water-bodies and pollution, p. 385-404. In P.D. Armitage, P.S. Cranton and L.C.V. Pinder (eds.) The Chironomidae: biology and ecology of non-biting midages. Chapman and Hall, London, UK.

Luoto TP, 2009. A Finnish chironomid- and chaoborid-based in- ference model for reconstructing past lake levels. Quaternary Sci. Rev. 28:1481-1489.

Luoto TP, 2012. Intra-lake patterns of aquatic insect and mite remains. J. Paleolimnol. 47:141-157.

Nyman M, Korhola A, Brooks SJ, 2005. The distribution and diversity of Chironomidae (Insecta: Diptera) in western Finnish Lapland, with special emphasis on shallow lakes. Global Ecol. Biogeogr. 14:137-153.

Oliver DR, Roussel ME, 1983. The insects and arachnids of Canada. 11. The genera of larval midges of Canada. Diptera: Chironomidae. Canada Department of Agriculture ed., Ottawa, Canada: 263 pp.

Rieradevall M, Brooks SJ, 2001. An identification guide to subfossil Tanypodinae larvae (Insecta: Diptera: Chironomidae) based on cephalic setation. J. Paleolimnol. 25:81-99.

Schmäh A, 1993. Variation among fossil chironomid assemblages in surficial sediments of Bodensee-Untersee (SWGermany): implications for paleolimnological interpretation. J. Paleolimnol. 9:99-108.

Shannon CE, Weaver W, 1963. The mathematical theory of communication. University of Illinois Press, Urbana, IL, USA.

ter Braak CJF, 1987. The analysis of vegetation-environment relationships by canonical correspondence analysis. Plant Ecol. 69:69-77.

ter Braak CJF, Šmilauer P, 2002. CANOCO reference manual and CanoDraw for Windows user's guide: software for canonical community ordination (version 4.5). Microcomputer Power Publ., Ithaca, NY, USA.

Walker IR, 2001. Midges: Chironomidae and related Diptera, p. 43-66. In: J.P. Smol, H.J.B. Birks and W. Last (eds.) Tracking environmental change using lake sediments. Vol. 4: zoological indicators. Kluwer Academic Publishers, Dordrecht, The Netherlands.

Walker IR, Cwynar LC, 2006. Midges and palaeotemperature reconstruction - the North American experience. Quaternary Sci. Rev. 25:1911-1925.

Wang S, Dou H, 1998. Lakes in China. Science Press, Beijing, China.

Wetzel RG, 2001. Limnology: lake and river ecosystems. Academic Press, San Diego, CA, USA.

Wiederholm T, 1983. Chironomidae of the Holarctic Region. Keys and diagnoses. I. Larvae. Entomol. Scand. Suppl. 19: 457 pp.

Wu G, Zhang Q, Zheng X, Mu L, Dai L, 2008. Water quality of Lugu Lake: Changes, causes and measurements. Int. J. Sust. Dev. World 15:10-17.

Zhang EL, Bedford A, Richard J, Shen J, Wang SM, Tang HQ, 2006. A subfossil chironomid-total phosphorus inference model from the middle and lower reaches of Yangtze River lakes. Chinese Sci. Bull. 51:2125-2132.

Zhang EL, Jones R, Bedford A, Langdon PG, Tang H, 2007. A chironomid-based salinity inference model from lakes on the Tibetan Plateau. J. Paleolimnol. 38:477-491.

Zhang EL, Langdon P, Tang HQ, Richard J, Yang XD, Shen J, 2011. Ecological influences affecting the distribution of larval chironomid communities in the lakes on Yunnan Plateau, SW China. Fund. Appl. Limnol. 179:103-113.

Zhang EL, Liu EF, Jones R, Langdon P, Yang XD, Shen J, 2010. A 150-year record of recent changes in human activity and eutrophication of Lake Wushan from the middle reach of the Yangtze River, China. J. Limnol. 69:235-241. 